paratively young people in association with movable kidney, the latter should be fixed.

The anatomy of the operation described has been revised by Professor Arthur Robinson, and to him $\mathrm{my}$ best thanks are due for his valuable assistance.

\section{A NOTE ON CRYOSCOPY OF URINE.}

BY W. R. GELSTON ATKINS, B.A.,

DEMONSTRATOR OF CHEMISTRY, TRINITY COLLEGE, DUBLIN.

WHEN an appreciable quantity of any pathological product is present in urine the depression of its freezing point below that of pure water does not give a correct indication of the functional activity of the kidney excreting it with relation to the elimination of the normal products of metabolism.

The depression of freezing point of water is proportional to the number of gram-molecules of dissolved substances in it, and is independent of the nature of those substances for non-electrolytes. It is for this reason that it is legitimate to use the depression as an indication of the work done by the kidney in eliminating the dissolved substances against the osmotic pressure produced by them for this pressure is also proportional to the number of gram-molecules in solution.

V. Koryani and others have shown that the value of the depressing of freezing point $\Delta$, does not fall below $09^{\circ} \mathrm{C}$. unless an unusual quantity of fluid has been taken. From this we conclude that a kidney producing arine which freezes at $-1.27^{\circ} \mathrm{C}$, for example, is functioning sufficlent]y to maintain health. But this conclusion may be quite wrong if it happens that a large quantity of a pathological product is present.

Sugar (glucose) is the substance most commonly met with in quantity, so it alone will be considered here. Su ppose that in the above specimen of urine freezing at $-127^{\circ}$ C., 5 per cent. of glucose be lound. This amoun of glucose, if dissolved in pure water, would lower it freezing point by a definite amount, and the presence of the other substances in no way interferes with thls. Accordingly, if we wish to determine whether the kidney is excreting waste products efficiently, we must find out the depression produced by the normal waste products alone : in other words, it is necessary to subtract from the depression as determined the depression produced by the quantity of glucose.

This was found by experiment originally, but cun now be easily calculated from the following equation:

$$
\mathbf{M}=\frac{\mathbf{s}}{\mathbf{L}} \times \frac{\mathbf{K}}{\Delta}
$$

In this $M$ represents the molecular weight of the dissolved substance, and $s$ the weight of it in $I$ grams of solvent; $\Delta$ is the depression of freezing point of the solution below that of the pure solvent, while $K$ is a constant depending upon the solvent. A full explanation of the equation would bo out of place here, but may be found in any book on physical chemistry, such as Walker, Lohfeldt, Ostwald, or Reychler. Now for moderate concentrations for $\frac{\mathrm{s}}{\mathrm{s}}$ we may, without serious error substitute $\frac{n}{100}$ the fractlonal amount of s present, then

$$
\mathbf{M}=\frac{\mathbf{p}}{100} \times \frac{\mathbf{k}}{\Delta}
$$

For water, $K=1870$, and the molecular weight of glucose $\mathrm{C}_{6} \mathrm{H}_{12} \mathrm{O}_{6}$ is 180 ; accordingly the depression produced by 5 per cent. of glucose dissolved in water can be calculated.

$$
180=\frac{5}{10 J} \times \frac{1870}{\Delta} \therefore \Delta=056^{\circ} \mathrm{C} \text {. }
$$

That is, $0.112^{\circ} \mathrm{C}$. for every 1 per cent. of glucose, which agfees well with the value $0104^{\circ} \mathrm{C}$, the mean of several concor Jant experimental determinations.

So it is clear that the depression produced by the normal products of metabolism contained in the urine is $1.27^{\circ} \mathrm{C} .-0.56^{\circ} \mathrm{C} .=071^{\circ} \mathrm{C}$, a value which is much too low. Thu this kidney, which would have been able to ellminate the quantities of solids occurring in orJinary metabolism, is unable to ellminate them in addition to the glucose. The difference must be accumulating in the blood, namely, solids sufficient to depres 3 the freezing point from $-0.71^{\circ} \mathrm{C}$, to $-0.90^{\circ} \mathrm{C}$. or more, and in addition probably some sugar, for there is no reason why all the sugar should be excreted while all the urea and other normal products are not. This accumulation will canse the blood to freeze below its normal point $-0.56^{\circ} \mathrm{C}$, gradually lowering it to $-0.60^{\circ} \mathrm{C}$. and beyond, till death ensues. Such a conclusion could not be drawn from one determination alone, but requires the weighing of any other facts that may be known, such as whether the other kidney is badly diseased, not developed, or has been removed by operation.

For example, a specimen sent for examination contained 1.87 per cent of glucose, and froze at $1.17^{\circ} \mathrm{C}$. Calculation showed the depression produced by the glucose alone to be $-0.19^{\circ} \mathrm{C}$., so the freezing point of the specimen, as far as the amount of normal products eliminated was concerned, was $-\left(1.17^{\circ}\right.$ C. $-0.19^{\circ}$ C. $)=-098^{\circ}$ C. This value, though low, is above the limit, and, taking into consideration the large volume of urine eliminated by diabetic patients, it would probably be safe to conclude that the kidney was iunctioning well.

Another specimen contained 7 per cent. glucose, and froze at $-2.11^{\circ} \mathrm{O}$. The depression produced by the glucose was calculated to be $-0.73^{\circ} \mathrm{C}$., so the "corrected" value of the freezlng point was $-1.38^{\circ} \mathrm{C}$. What has been said of glucose holds equally well for any other pathological product.

For convenience a table is added showing the depression of freezing point of water by varions quantities of glucose given to the nearest hundredth of $\mathrm{a}$ degree, and based on the value $\Delta=0.104^{\circ} \mathrm{C}$. for a 1 per cent. solution. The figures in the region of 10 per cent. are slightly too high, as for great concentrations the law. is not strictly correct; these deviations amount to only $0.02^{\circ} \mathrm{C}$. at 6 per cent., and increase slight]y with the concentration.

Table slowing Depression of Freezing Point by Various Qunntities or Glucose.

\begin{tabular}{c|c||c|c}
\hline Glucose per Cent. & $\Delta$ & Glucose per Cent. & $\Delta$ \\
\hline \multirow{2}{\frac{1}{2}}{} & -0.05 & $5 \frac{1}{2}$ & $0 \mathbf{C}$ \\
\hline 1 & -0.10 & 6 & -0.57 \\
$1_{\frac{1}{2}}$ & -0.16 & $\epsilon_{\frac{1}{2}}$ & -0.62 \\
2 & -0.21 & 7 & -0.68 \\
$2 \frac{1}{2}$ & -026 & $7 \frac{1}{2}$ & -0.73 \\
3 & -031 & 8 & -078 \\
$3 \frac{1}{2}$ & -036 & $8 \frac{1}{2}$ & -0.83 \\
4 & -042 & 9 & -0.88 \\
$4 \frac{1}{2}$ & -0.47 & $9 \frac{1}{2}$ & -094 \\
5 & -0.52 & 10 & -099 \\
& & & -1.04 \\
\hline
\end{tabular}

With regard to the technique of freez!ng-point determinations of urine and blood, those who claim to make these measurements in twenty minutes are liable to encounter an error, not very serious where urine is concerned, but of relatively great magnitude when blood is being examined. When, in order to determine the scalereading corresponding to $0.00^{\circ}$ C., the balb of the Beckmann thermometer is placed in $a$ well-stirred mixture of ice and water, the mercury quickly contracts and comes to rest at, say, 1.35 after $\mathrm{a}$ few minutes. But this is not the true zero, for on allowing the thermometer to stand for some time, with constant stirring, the zero will be found to have rigen to 1.37 or thereabouts. This occurs because the large and very thin glass bulb contracts appreciably, but more slowly than the mercury; accordingly the mercury thread is gradually forced up. This rise was observed to be $0.02^{\circ} \mathrm{C}$. in three Beckmann thermometers examlned, and ceased to be appreciable after, roughly, one hour. These thermometers had only been exposed to the ordinary air temperatures of the laboratory for some months previously; but in the case of thermometers which have been exposed to any considerable temperature the error would be much more serious.

The effect is, of course, to cause the freezing point of the blood, $\delta$, to have too low a numerlcal value, if the zero rices in the interval between its determination and the 
determination of $\delta$. Thus a specimen which has a true freezing point, $-061^{\circ} \mathrm{C}$, indicating an advanced state of disease, may appear to have a value $\delta=0.58^{\circ} \mathrm{C}$., a normal value, if the zero has shifted $0.03^{\circ} \mathrm{C}, \mathrm{a}$ by no means unlikely amount in warm weather.

\section{SUPPURATIVE APPENDICITIS IN A PATIENT WITH TRANSPOSED VISCERA.}

BY HAROLD HEBBLETHWATTE, M.R.C S.ENG; BURLEY-IN-WHARFRDALE.

INSTANC8s of transposition of the viscera are sufficiently rare to be of interest, and the following notes on a case of appendicitis in the left slde are worthy of record on account of the rarity of the condition and the lack of symptoms pointing to the severity of the disease.

A tall, thin, fair-complexioned boy, aged 16. With the exception of mild attaoks of the usual exanthemsta had never had any Illness worthy of mention, and to the day prior to my seeing him had been at school, apparently in good health.

On physical examination it was at once seen that the posItion of the Internal organs was abnormal. The heart apex was felt in the fifth intercostal space, $1_{\frac{1}{2}}$ in. to the right of the sternum, and the heart dullness was ail on the right side. The

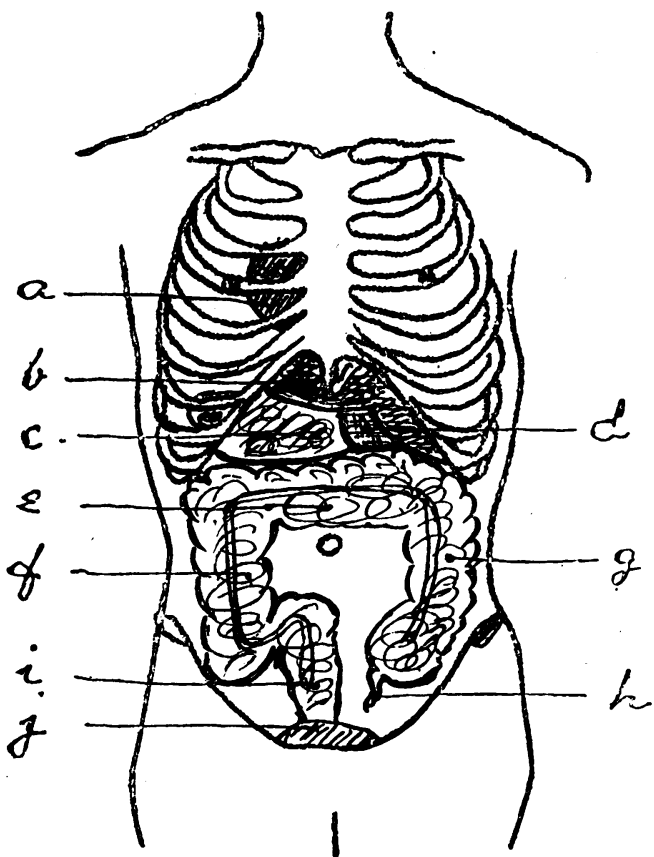

Transposition of viscera (Kelly's vermiform appendix). $a$, Heart; $b$, liver; $c$, stomach ; $a$, gall bladder; $e$, transverse colon; $f$, descending colon; $g$, caecum : $h$, vermiform appendix; , rectum; $j$, bladder.

liver could be paipated on the left, and the resonance of the stomach elicited on the opposite side. The heart sounds corresponded to the unusual position, the second sound being londest in the second left interspace.

On Mey $17 \mathrm{th}, 1906$, he returned from school complaining of sickness and prin in the sbdomen. On examination the sickness and pain in the abdomen. On examination the following day the abdomen was tense bat not very tender; his breakfast ; the temperature was $100.5^{\circ}$ and the pulse 70 . He said that he did not feel very ill, nor did his looks indicate any severe condition. In twenty-four hours, however, the pain returned and the abdomen was distended. Both flanks were very palnful on pressure but distinctly more on the left side. The probable transposition of the appendix into the left llieo fosen led me to suspeot that organ to be the canse of the tro with this opinion, and we treated tho case on expectant lines with a view to an operation when the acute symptoms passed off. For the first forty-eight hours the patient was not allowed any food, and for some days after only egg albumen solution and veryilight food, the bowels being acted upon by glycerine or simple enemsta. Daring the next fortnight the symptoms somewhat abated, and occasional pain on the right side, as of peritonitis, was relievad by turpentine stupes; the generel malsise did not quite subside ; there was occeslonal vomiting; the temperatare seated pain was produced by pressure on the left lliac region, and there was o want of resonance on percussion.

An operation was performed by Mr. Moyniban on Jane $12 \mathrm{th}$ ether being the anaesthetic. A preliminary insision 5 in. long in the central line, to locate the appendix definitely, revealed an unexpected condition. The whole peritoneum showed signs of old peritonitis ; the Intestinal colls were adherent, and numerous bands were felt. These were broken
as much as possible before closing the wound. The abdominal as much as possible before closing the wound. The abdominal extending from a point 3 in. to the left of the umbilicus downwards and inwards for a distance of $7 \mathrm{in}$. to the central line was then made. On opening the peritoneum it was found that the left iliac region was occupied by an abscess contsining foul pus; the appendix was in a gangrenous state, and a perfora lion of the con tubes were inserted in the wounds, and the cavity left to

tubes

The patient rapldly recovered from the shock of the operation. The temperature, which had been subinormal for nearly three weeks, rose to $100.5^{\circ}$ on that evering. It kept af terwards about $99^{\circ}$, and slowly sank to normal.

The abscess cavity was Irrigated twice daily with stexillzed water and peroxide of hydrogen. Faecal matter appeared in the dressings until the end of July, and - the sinus finslly hesled in the last week of August.

Points of interest in the case are: First, the very slight inflammatory symptoms preceding so large a collection of pus; secondly, the absence of any history of previous illness to account for the extensive adhesions over the whole peritoneum, and the rapid and complete healing of the perforation from the sloughing appendix.

\section{The Science Committee OF THE Britisb medical Rssociation. IREPORT CIII.}

THE HALDANE-SMITH METHOD OF ESTIMATING THE OXYGEN TENSION OF ARTERIAL BLOOD.

BY W. A. OSBORNE.

(From the Plipsiological Laboratory, University of Melbourne.) [ABSTRACT.]

THE theory of the method depends upon the fact that both oxygen and carbon monoxide form dissociable com pounds with haemoglobin. If haemoglobin be subjected to a mixture of both $\mathrm{O}_{2}$ and $\mathrm{CO}$, the haemoglobin will be distributed according to a law which may be expressed in the form of an equation:

$$
\frac{p_{\mathrm{CO}}}{p_{\mathrm{O}_{2}}}=\mathrm{K} \frac{\mathrm{C}_{\mathrm{COHb}}}{\mathrm{C}_{\mathrm{O}_{2} \mathrm{Hb}}}
$$

where $p_{\text {co }}$ and $p_{\mathrm{O}_{2}}$ are the pressures of carbon monoxide and oxygen respectively, $\mathrm{C}_{\mathrm{COHb}}$ and $\mathrm{C}_{\mathrm{O}_{2} \text { Hb }}$ the concentrations of carboxyhremoglobin and oxyhaemoglobin respectively, and $K$ a constant.

If the amount of haemoglobin unattached to either $\mathrm{O}_{2}$ or $\mathrm{CO}$ be negligibly small, as it is in the experiments in question, we may write this equation as follows:

$$
\frac{p_{\mathrm{CO}}}{p_{\mathrm{O}_{2}}}=\mathrm{K}=\frac{a}{100-a}
$$

where $a$ ls the percentage saturation of the haemoglobin with $\mathrm{CO}$. In the experiments of Haldane and Smith an animal breathed a definite percentage of $\mathrm{CO}$ in air giving therefore $\boldsymbol{p}_{\mathrm{Co}}$. The percentage saturation of the blood was determined by a colorimetric method. The constant $\mathrm{K}$ can be calculated if we know the curve of dissociation of carboxyhaemoglobin in the presence of a fixed pressure of oxygen. In these experiments of Haldane and Smith the blood of the animal was found to contain less carboxyhaemoglobin than 11 the blood was shaken in vitro with the aame gas mixture. If the experiments were correct, and no purely physical explanation of the fact forthcoming, and if it be granted that the lung does not do work by keeping $\mathrm{CO}$ out, then we must assume that the lung does work by forcing oxygen into the blood against pressure. From these experiments of Haldane and Smith calculated that the arterial blood of man contained oxygen at a pressure of 385 per cent. of an atmosphere.

In criticizing these researches it can be shown:

1. That the colorimetrlc method cannot give reliable results, as it violates two fundamental laws of colorimetry. 